\title{
Age-related Features of the Cytological Diagnosis of Cervical Dysplasia of Different Degrees
}

\author{
Maria P. Kirillina, $\mathrm{PhD}^{1,2^{*}}$; Sargylana I. Sofronova, $\mathrm{PhD}^{1}$; Irina V. Kononova, $\mathrm{PhD}^{1}$; \\ Anna K. Ivanova ${ }^{2}$; Elena L. Lushnikova, $\mathrm{PhD}, \mathrm{ScD}^{3}$ \\ ${ }^{1}$ Yakut Science Centre of Complex Medical Problems, Yakutsk, Russia \\ ${ }^{2}$ M. K. Ammosov North-Eastern Federal University, Yakutsk, Russia \\ ${ }^{3}$ Federal Research Center of Fundamental and Translational Medicine, Novosibirsk, Russia
}

\begin{abstract}
The purpose of this study was to investigate the incidence of cervical intraepithelial neoplasia (CIN) and cervical cancer (CC) in women of different age groups who underwent cervical cytological testing from 2016 to 2018. According to our study, the frequency of CD incidence was inversely dependent on the degree of dysplasia in all age groups of women receiving survey from 2016 to 2018. The CIN1 incidence rate increased from 2016 to 2018, while the rate of CIN 2, CIN 3 and CC decreased. An analysis of the distribution patterns of CIN 1, CIN 2, CIN 3 and CC according to age revealed that the peak ages of the CIN1-3 incidence was 26-35 years. In the age group of 46-55 years, there was a sharp increase in CC - by 2.5 times compared with the age groups of 26-35 years and 36-45 years. Although the peak ages of CC incidence was $\geq 56$ years. The peak ages of the indirect signs of HPV infection were 18-29 years and 30-44 years, characterizing the peculiarity of the immune status of these age groups. Thus, the peak age group in which women develop both CIN1 and CIN2+ is 26-35. Patient's age has a considerable influence on the natural history of CIN-independent of CIN grade and HPV high-risk infection. (International Journal of Biomedicine. 2019;9(4):324-328.)
\end{abstract}

Key Words: cervical intraepithelial neoplasia $\bullet$ cervical cancer • human papillomavirus

\section{Abbreviations}

CC, cervical cancer; CIN, cervical intraepithelial neoplasia; CD, cervical dysplasia; LSIL, low-grade squamous intraepithelial lesion; HSIL, high-grade squamous intraepithelial lesion; HPV, human papillomavirus.

\section{Introduction}

According to the Russian statistics, in 2016, 16,423 new cases of cervical cancer (CC) were recorded. In the structure of the morbidity of the female population with malignant neoplasms, CC occupies fifth place $(5.3 \%){ }^{(1)}$ Invasive CC is preceded by a long phase of pre-invasive disease called cervical intraepithelial neoplasia (CIN), also known as cervical dysplasia (CD). CINs ascertained by histological examination

*Corresponding author: Maria P. Kirillina, PhD. M. K. Ammosov North-Eastern Federal University. Yakutsk, Russia. E-mail: kirillinamp@mail.ru are classified in three grades based on increasing degrees of cellular change and disorganization. The strongest factor influencing the natural history of CIN is the presence of highrisk human papillomavirus (HPV) infection. ${ }^{(2,3)}$ In particular HPV 16 and 18 increase the risk for persistent disease. ${ }^{(4)}$ Lowgrade squamous intraepithelial lesion (LSIL, also known as CIN1) is now recognized as a histological diagnosis of benign viral replication that should be managed conservatively. Despite evidence on differences in the clinical course of CIN2 and CIN3, the updated World Health Organization 2014 histopathological classification graded these lesions as a single entity: high-grade squamous intraepithelial lesion (HSIL). ${ }^{(5)}$ If left untreated, CIN2 or CIN3 (collectively referred to as CIN2+) can progress to CC. It is estimated that approximately $1 \%-2 \%$ of women 
have CIN2+ each year, with higher rates reported for women of HIV-positive status, at $10 \%{ }^{(6-10)} \mathrm{A}$ recent 5 -year longitudinal investigation from Northern Italy ${ }^{(11)}$ of 310 patients with CIN2+ indicates that none of the 172 women with a negative HPV DNA test at 6 months post-treatment had residual or recurrent CIN2+ during the 2-year surveillance period. Thus, the authors conclude that that HPV DNA is highly predictive of disease eradication.

According to a study conducted in the United States, the annual incidence of CIN 1 was 1.2 per 1,000 with a rate of 1.5 per 1,000 for CIN 2/3. CIN 1 incidence peaked among women aged 20 to 24 years $(5.1$ per 1,000), with CIN $2 / 3$ rates highest among those 25 to 29 years $(8.1$ per 1,000$) .{ }^{(12)}$ Another US study found that 412,000 women in the United States are diagnosed with CIN annually, with an associated cost of approximately $\$ 570$ million. CIN incidence was highest among women aged 21 to 30 years $(3.3$ and 3.6 per 1,000 ) and women aged 31 to 40 years $(2.9$ and 2.7 per 1,000$) \cdot{ }^{(13)} \mathrm{CC}$ tends to occur in midlife and is most frequently diagnosed in women between the ages of 35 and $44 .{ }^{(14)}$ According to the Russian statistics, the incidence of CC was the highest in the age group of 30-34 years (23.76\%), compared with other age groups. ${ }^{(1)}$

The purpose of this study was to investigate the incidence of CIN and CC in women of different age groups who underwent cervical cytological testing from 2016 to 2018 .

\section{Materials and Methods}

Cytological material with signs of $\mathrm{CD}$ of different degrees from 931 women aged between 18 and 88 years, who applied to medical institutions for preventive and diagnostic purposes from 2016 to 2018, was analyzed in the laboratory of pathomorphology, histology and cytology of the NEFU Medical Institute Clinic. The material of the cytological study consisted of smears of cervical mucosa and the cervical canal, stained according to the method of Romanovsky-Giemsa. Diagnosis of CIN (1-3) and CC was performed according to Bokhman's classification (1976). We conducted a comparative study for the incidence of $\mathrm{CD}$ in the dynamics of a 3-year examination period by year (2016, 2017 and 2018). The study was conducted with subjects grouped according to age: the age groups of $18-25$ years $(n=144 / 15.5 \%), 26-35$ years $(n=222 / 23.8 \%), 36-45$ years $(n=212 / 22.7 \%), 46-55$ years $(\mathrm{n}=192 / 20.6 \%)$, and $\geq 56$ years $(\mathrm{n}=161 / 17.3 \%)$.

\section{Results and Discussion}

In accordance with the years of the survey, $128(13.7 \%)$ women underwent a cytological study in 2016, 322(34.5\%) women in 2017, and 481(51.6\%) women in 2018. According to the data of cytological analysis, the highest rate falls on LSIL (CIN1), which was recorded in 578(62.1\%) women. HCIL (CIN2 and CIN3) were found in 241(25.9\%) and 97(10.4\%) women, respectively (Fig. 1, 2). CC was detected in $15(1.6 \%)$ examined women (Fig. 3). The high frequency of CIN1 may reflect a high prevalence HPV in examined women. In addition, CIN1 may not be a true neoplastic lesion and just reflects the changes due to HPV infection and be difficult to distinguish from reactive and other non-neoplastic histological changes that resolves spontaneously. Generally, CIN1, as acute infection, has a high regression rate with recommended management.

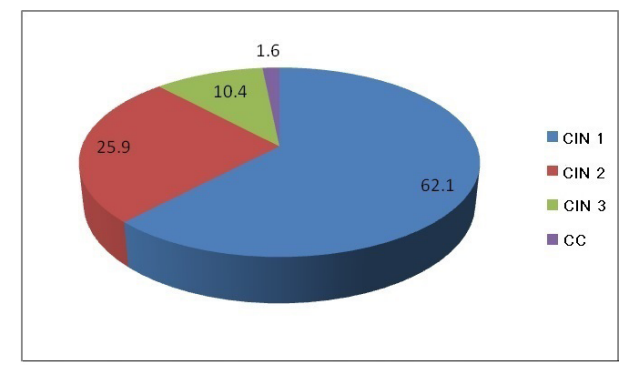

Fig.1. The incidence of different types of CIN and $C C$ in women who underwent cervical cytological testing from 2016 to 2018.
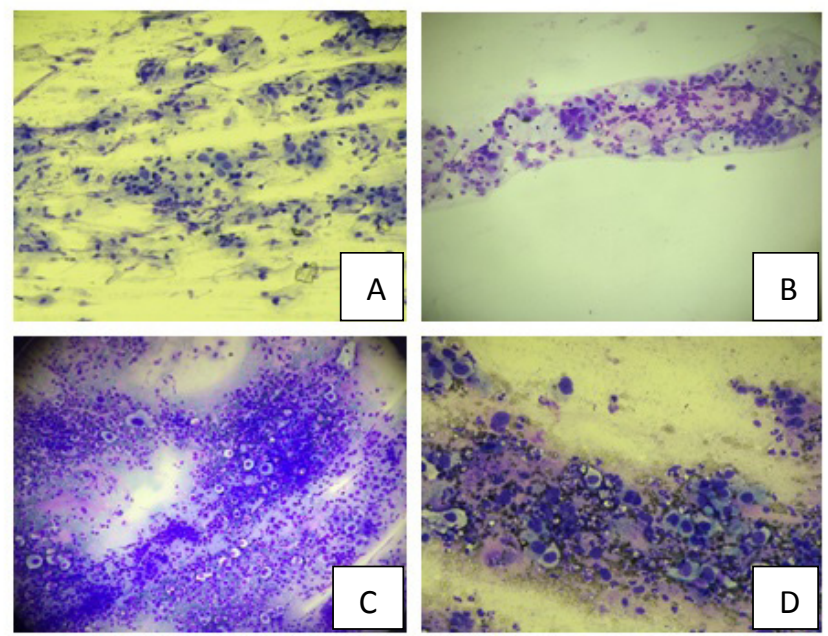

Fig. 2. $A-C I N ~ 1, B-C I N 2, D-C I N 3 ; x 200$
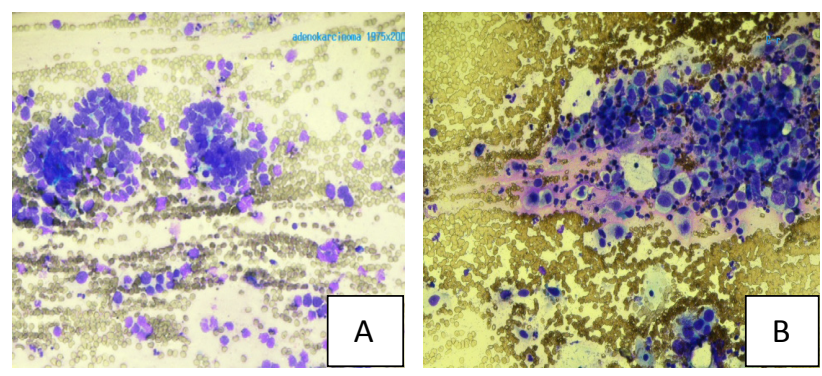

Fig. 3. A-cervical adenocarcinoma, B-squamous cervical cancer; $x 200$.

Analysis of the frequency of different types of CD and CC over a 3-year period (from 2016 to 2018 inclusive) (Fig.4) showed an increase in the CIN1 rate from year to year with a simultaneous decrease in the rate of CIN2 and CIN3. The incidence of CIN1 in 2018 increased by $52.6 \%$ compared to 2016 , while the incidence of CIN2 decreased by $24.3 \%$, and the incidence of CIN3 decreased by 3.33 times. The CC incidence decreased by 2.2 times over a three-year period. 
This indicates a positive trend in the development of highgrade dysplasia. The decrease in the rate of CIN2+ and CC can be associated with constant monitoring of the development of dysplasia in the dynamics and effective treatment.

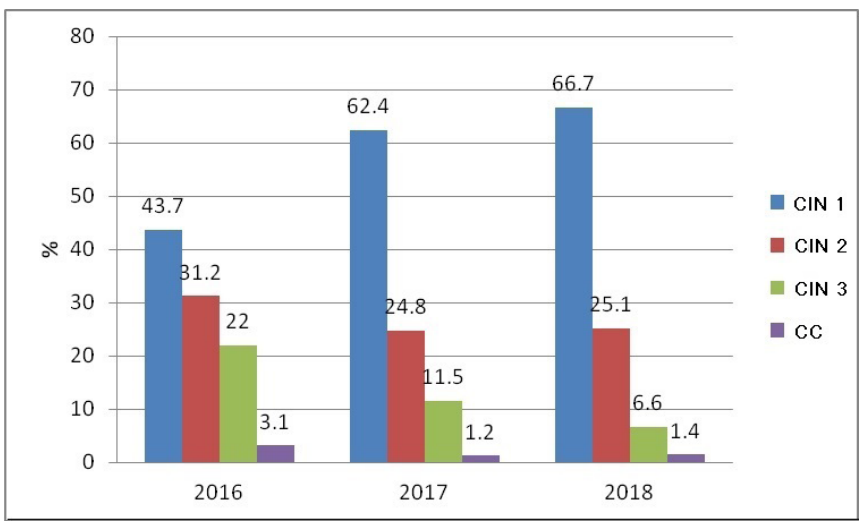

Fig.4. The frequency dynamics of different types of $C D$ and $C C$ over a 3-year period (from 2016 to 2018 inclusive).

A study of the incidence of CD depending on age showed that CIN1 was the most frequently diagnosed pathology in all age groups.(Fig.5) The highest frequency of CIN1 (14.2\%) was observed in the age group of 26-35 years, the lowest frequency $(10 \%)$ was observed in the age group of $\geq 56$ years. The highest frequency of CIN2 (6.4\%) was observed in the age groups of 26-35 years and 36-45 years. The lowest frequency of CIN2 (3.7\%) was found in the age group of 4655 years. The highest frequency of CIN3 (3\%) was observed in the age group of 26-35 years, and the minimum frequency of CIN3 (0.8\%) in the age group of 18-25 years. The incidence of CC increased depending on the age of the patients. In the age groups of $46-55$ years and $\geq 56$ years, this indicator was 2.5 and 3 times higher, respectively, than in the age group of 26-45 years (with no cases in the age group of 18-25 years). The maximum incidence of $\mathrm{CC}$ was observed in the age group of $\geq 56$ years $-6(0.6 \%)$ cases. Thus, the progression of the severity of CD develops over decades, and as the severity of $\mathrm{CD}$ increases, the risk of further progression increases and the chance of regression decreases.

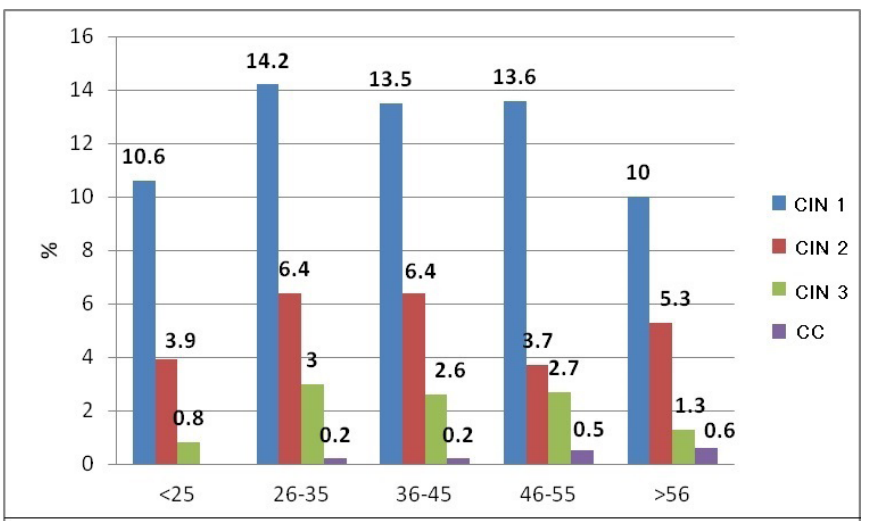

Fig.5. The incidence of $C D$ in different age groups.
The link between HPV and CC has been extensively investigated over the past decade. ${ }^{(15)}$ In the majority of HPVinfected individuals, the virus will clear out naturally. An immune-deficient woman will develop CC within 5 to 10 years, while for a woman with a normal immune system this time frame may be extended up to 15 to 20 years or even longer. ${ }^{(16)}$ Persistent infection with high-risk HPV types and altered viral gene expression are the cornerstone of HPVinduced carcinogenesis. ${ }^{(17)}$

HPV infection has specific sites for localization. In order to complete the HPV infection generation cycle, the virus requires a stratified epithelium. The usual progression begins with initial virus infestation of the basal cell nucleus, overcoming the host defense mechanisms. A long-recognized, pathognomonic feature of HPV infection is the appearance of halo or koilocytotic cells in the differentiated layers of the squamous epithelium. ${ }^{(18)}$

The maximum incidence of indirect signs of HPV infection was observed in the age group of 26-35 years. (Fig.6, 7 ) It is estimated that in about $70 \%$ of young women, HPV infection spontaneously disappears after 12 months from the date of detection. Long-term preservation of HPV linked mainly to infection by high-risk HPV types (mainly HPV 16 and 18). ${ }^{(4)}$ In menopausal women, indirect signs of viral infection were rare.

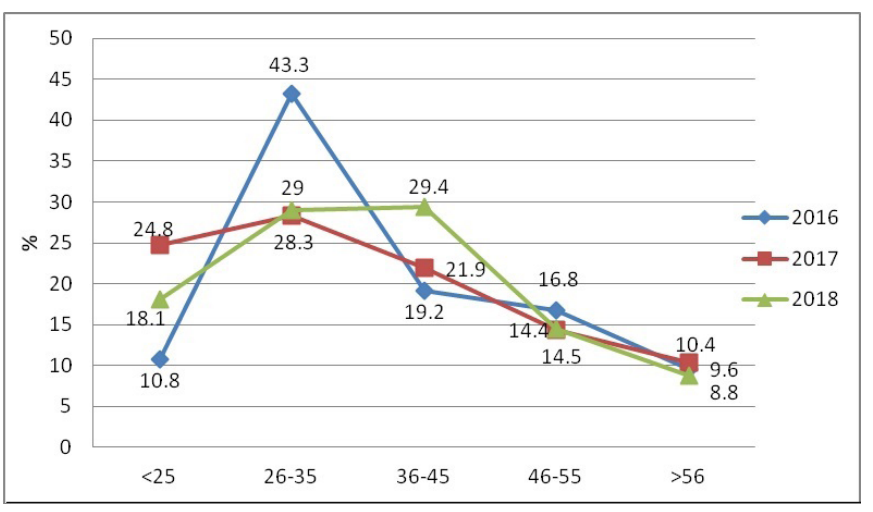

Fig.6. The incidence of indirect signs of HPV infection in different age groups.

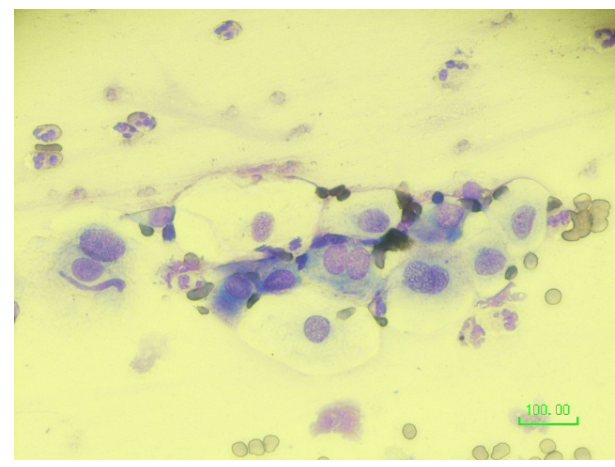

Fig.7. Binucleated cells with their nuclei pressing against each other in a smear from the cervix in HPV infection. Romanowsky-Giemsa staining; $x 400$. 


\section{Conclusion}

Thus, according to our study, the frequency of CD incidence was inversely dependent on the degree of dysplasia in all age groups of women receiving survey from 2016 to 2018. The CIN1 incidence rate increased from 2016 to 2018, while the rate of CIN 2, CIN 3 and CC decreased. An analysis of the distribution patterns of CIN 1, CIN 2, CIN 3 and CC according to age revealed that the peak ages of the CIN1-3 incidence was 26-35 years. In the age group of 46-55 years, there was a sharp increase in CC - by 2.5 times compared with the age groups of 26-35 years and 36-45 years. Although the peak ages of $\mathrm{CC}$ incidence was $\geq 56$ years. The peak ages of the indirect signs of HPV infection were 18-29 years and 3044 years, characterizing the peculiarity of the immune status of these age groups.

Thus, the peak age group in which women develop both CIN1 and CIN2+ is 26-35. The age group of 46-55 years and older presents a sharp increase in CC incidence. Patient's age has a considerable influence on the natural history of CINindependent of CIN grade and HPV high-risk infection. Observational management should be considered for selected young patients with CIN. ${ }^{(19-22)}$

Prevention, early detection, and effective treatment of malignant tumors is one of the most important sections of modern medicine. The WHO guideline provides recommendations for screening and treatment of precancerous lesions to prevent CC. A new screen-and-treat strategy applies to all women regardless of HIV status, but specific recommendations for women living with HIV have been developed. ${ }^{(23)}$

\section{Competing Interests}

The authors declare that they have no competing interests.

\section{References}

1. Kaprin AD, Starinsky VV, Petrova GV. Malignant neoplasms in Russia in 2016 (morbidity and mortality). M.: P. A. Hertsen Moscow Oncology Research Center (branch of FSBI NMRRC of the Ministry of Health of Russia); 2018. [In Russian].

2. Munoz N, Bosch FX, de Sanjose S, Herrero R, Castellsague $\mathrm{X}$, Shah KV, et al. Epidemiologic classification of human papillomavirus types associated with cervical cancer. $\mathrm{N}$ Engl $\mathrm{J}$ Med. 2003;348(6):518-27.

3. Darragh TM, Colgan TJ, Cox JT, Heller DS, Henry MR, Luff $\mathrm{RD}$, et al. The lower anogenital squamous terminology standardization project for HPV-associated lesions: background and consensus recommendations from the College of American Pathologists and the American Society for Colposcopy and Cervical Pathology. Arch Pathol Lab Med. 2012;136(10):1266-97.

4. Moscicki AB, Shiboski S, Broering J, Powell K, Clayton L, Jay N, Darragh TM, et al. The natural history of human papillomavirus infection as measured by repeated DNA testing in adolescent and young women. J Pediatr. 1998:132(2):277-84.
5. World Health Organization. WHO guidelines for treatment of cervicalintraepithelial neoplasia 2-3 and adenocarcinoma in situ. Geneva: World Health Organization; 2014. Available at: https://apps.who.int/iris/bitstream/ handle/10665/104174/9789241506779 eng.pdf? sequence $=1$

6. Arbyn M, Ronco G, Anttila A, Meijer CJ, Poljak M, Ogilvie G, et al. Evidence regarding human papillomavirus testing in secondary prevention of cervical cancer. Vaccine. 2012;30 Suppl 5:F88-99. doi: 10.1016/j.vaccine.2012.06.095. 7. De Vuyst H, Mugo NR, Chung MH, McKenzie KP, Nyongesa-Malava E, Tenet V, et al.Prevalence and determinants of human papillomavirus infection and cervical lesions in HIV-positive women in Kenya. $\mathrm{Br} \mathrm{J}$ Cancer. 2012;107(9):1624-30. doi: 10.1038/bjc.2012.441.

8. Joshi S, Sankaranarayanan R, Muwonge R, Kulkarni V, Somanathan T, Divate U. Screening of cervical neoplasia in HIV-infected women in India. AIDS. 2013;27(4):607-15. doi: 10.1097/QAD.0b013e32835b1041.

9. Denny L, Boa R, Williamson AL, Allan B, Hardie D, Stan R, Myer L. Human papillomavirus infection and cervical disease in human immunodeficiency virus-1-infected women. Obstet Gynecol. 2008;111(6):1380-7. doi: 10.1097/ AOG.0b013e3181743327.

10. Zhang HY, Tiggelaar SM, Sahasrabuddhe VV, Smith JS, Jiang CQ, Mei RB, et al. HPV prevalence and cervical intraepithelial neoplasia among $\mathrm{HIV}$-infected women in Yunnan Province, China: a pilot study. Asian Pac J Cancer Prev. 2012;13(1):91-6.

11. Garutti P, Borghi C, Bedoni C, Bonaccorsi G, Greco P, Tognon M, et al. HPV-based strategy in follow-up of patients treated for high-grade cervical intra-epithelial neoplasia: 5 -year results in a public health surveillance setting. Eur J Obstet Gynecol Reprod Biol. 2017;210:236-241. doi: 10.1016/j.ejogrb.2016.12.018.

12. Insinga RP, Glass AG, Rush BB. Diagnoses and outcomes in cervical cancer screening: a population-based study. Am J Obstet Gynecol. 2004;191(1):105-13.

13. Henk HJ, Insinga RP, Singhal PK, Darkow T. Incidence and costs of cervical intraepithelial neoplasia in a US commercially insured population. J Low Genit Tract Dis. 2010; 14(1):29-36. doi: 10.1097/LGT.0b013e3181ac05e9.

14. The American Cancer Society medical and editorial content team. Key Statistics for Cervical Cancer Available at: https://www.cancer.org/cancer/cervical-cancer/about/keystatistics.html.

15. Boda D, Docea AO, Calina D, Ilie MA, Caruntu C, Zurac $S$, et al. Human papilloma virus: Apprehending the link with carcinogenesis and unveiling new research avenues (Review). Int J Oncol. 2018;52(3):637-655. doi: 10.3892/ijo.2018.4256. 16. Stokley S, Jeyarajah J, Yankey D, Cano M, Gee J, Roark J, et al.; Immunization Services Division, National Center for Immunization and Respiratory Diseases, CDC; Centers for Disease Control and Prevention (CDC). Human papillomavirus vaccination coverage among adolescents, 2007-2013, and postlicensure vaccine safety monitoring, 2006-2014--United States. MMWR Morb Mortal Wkly Rep. 2014;63(29):620-4. 17. Doorbar J, Quint W, Banks L, Bravo IG, Stoler M, Broker TR, Stanley MA. The biology and life-cycle of human papillomaviruses. Vaccine. 2012 Nov 20;30 Suppl 5:F55-70. doi: 10.1016/j.vaccine.2012.06.083.

18. Krawczyk E, Suprynowicz FA, Liu X, Dai Y, Hartmann DP, Hanover J, Schlegel R. Koilocytosis: a cooperative interaction between the human papillomavirus E5 and E6 
oncoproteins. Am J Pathol. 2008;173(3):682-8. doi: 10.2353/ ajpath.2008.080280.

19. Massad LS, Einstein MH, Huh WK, Katki HA, Kinney WK, Schiffman M, et al.; 2012 ASCCP Consensus Guidelines Conference. 2012 updated consensus guidelines for the management of abnormal cervical cancer screening tests and cancer precursors. Obstet Gynecol. 2013 Apr;121(4):829-46. doi: 10.1097/AOG.0b013e3182883a34.

20. Fuchs K, Weitzen S, Wu L, Phipps MG, Boardman LA. Management of cervical intraepithelial neoplasia 2 in adolescent and young women. J Pediatr Adolesc Gynecol. 2007;20(5):269-74.

21. McCredie MR, Sharples KJ, Paul C, Baranyai J, Medley G, Jones RW, Skegg DC. Natural history of cervical neoplasia and risk of invasive cancer in women with cervical intraepithelial neoplasia 3: a retrospective cohort study. Lancet Oncol. 2008;9(5):425-34. doi: 10.1016/S1470-2045(08)70103-7.

22. Bekos C, Schwameis R, Heinze G, Gärner M, Grimm $\mathrm{C}$, Joura $\mathrm{E}$, et al. Influence of age on histologic outcome of cervical intraepithelial neoplasia during observational management: results from large cohort, systematic review, meta-analysis. Sci Rep. 2018;8(1):6383. doi: 10.1038/s41598018-24882-2.

23. World Health Organization. WHO guidelines for screening and treatment of precancerous lesions for cervical cancer prevention. Geneva: World Health Organization; 2013. Available at: https://apps.who.int/iris/bitstream/ handle/10665/94830/9789241548694_eng.pdf?sequence=1. 